\title{
Effects of Environmental Heat on Conception Rates in Lactating Dairy Cows: Critical Periods of Exposure
}

\author{
J. M. Morton, ${ }^{* 1}$ W. P. Tranter,† D. G. Mayer,ł and N. N. Jonsson* \\ *School of Veterinary Science, The University of Queensland, Queensland 4072, Australia \\ †Tableland Veterinary Service, Malanda, Queensland 4885, Australia \\ $\ddagger$ Animal Research Institute, Department of Primary Industries and Fisheries, Yeerongpilly, Queensland 4105, Australia
}

\begin{abstract}
Environmental heat can reduce conception rates (the proportion of services that result in pregnancy) in lactating dairy cows. The study objectives were to identify periods of exposure relative to the service date in which environmental heat is most closely associated with conception rates, and to assess whether the total time cows are exposed to high environmental heat within each 24-h period is more closely associated with conception rates than is the maximum environmental heat for each 24-h period. A retrospective observational study was conducted in 25 predominantly Holstein-Friesian commercial dairy herds located in Australia. Associations between weather and conception rates were assessed using 16,878 services performed over a 21 -mo period. Services were classified as successful based on rectal palpation. Two measures of heat load were defined for each 24-h period: the maximum temperature-humidity index (THI) for the period, and the number of hours in the 24-h period when the THI was $>72$. Conception rates were reduced when cows were exposed to a high heat load from the day of service to $6 \mathrm{~d}$ after service, and in wk -1 . Heat loads in wk -3 to -5 were also associated with reduced conception rates. Thus, management interventions to ameliorate the effects of heat load on conception rates should be implemented at least 5 wk before anticipated service and should continue until at least $1 \mathrm{wk}$ after service. High autocorrelations existed between successive daily values in both measures, and associations between day of heat load relative to service day and conception rates differed substantially when ridge regression was used to account for this autocorrelation. This indicates that when assessing the effects of heat load on conception rates, the autocorrelation in heat load between days should be accounted for in analyses. The results suggest that either weekly averages or totals summarizing the daily heat load are
\end{abstract}

Received September 6, 2006.

Accepted January 5, 2007.

${ }^{1}$ Corresponding author: j.morton@uq.edu.au adequate to describe heat load when assessing effects on conception rates in lactating dairy cows.

Key words: dairy cow, heat exposure, conception rate, environmental heat

\section{INTRODUCTION}

Environmental heat can reduce the reproductive performance of lactating dairy cows. In regions with hot summers, the time to conception is longer among cows that calve in spring and summer, relative to those calving in autumn and winter (De Rensis et al., 2002). There is some evidence that lower submission rates may contribute to these patterns. Time to first insemination was longer among cows that calved in summer rather than in winter (Jonsson et al., 1999), and cow body temperature in early lactation was positively associated with time to first ovulation (Jonsson et al., 1997).

Prolonged times to conception associated with hot weather are also due to reduced conception rates. Substantially lower conception rates were reported following services performed in hot months (Lopez-Gatius, 2003) and in seasons or months with higher temperature-humidity index (THI) values (McGowan et al., 1996). Although heat exposure on the day of service may have important effects on conception rates, services performed during hot periods are commonly preceded and succeeded by hot weather, and the effects on these days may be equal to or more important than conditions on the day of service. Environmental heat in the period around the day of service was consistently associated with reduced conception rates, but the precise effects of heat exposure at specific times are unclear. A maximum temperature above $27^{\circ} \mathrm{C}$ on the day of service was associated with reduced conception rates (Cavestany et al., 1985). In earlier work, the average THI from $2 \mathrm{~d}$ before service $(\mathrm{d}-2)$ to the day of service (d 0) was negatively associated with conception rates, and conditions $2 \mathrm{~d}$ before service were more closely associated with the chance of conception than conditions on $d-1,0$, or 1 (day after service; Ingraham, 1973) or on other days between -14 and +2 (Ingraham et al., 
1976). In contrast, in more recent work, the negative association between temperature and conception rates was similar regardless of whether temperature was assessed on $\mathrm{d}-10,0$, or +10 (Al-Katanani et al., 1999). Because weather can be highly correlated between successive time periods, these associations may not accurately reflect periods of greatest biological effects of environmental heat. This is because an observed association between a weather variable on any particular day and conception rate may be due, in part, to environmental heat before or after that day.

When assessing the effects of hot weather on reproductive performance, some researchers described environmental heat using air temperature (Al-Katanani et al., 1999). Nonetheless, thermoregulation in cows is affected not only by air temperature but also by relative humidity (Armstrong, 1994). Thus, the THI appears particularly useful because it is calculated using both air temperature and relative humidity data, both of which are commonly measured at weather stations. In most situations, air temperature and relative humidity vary during the day, necessitating the use of average (Ingraham et al., 1976; Al-Katanani et al., 1999) values for each 24-h period. However, it is possible that the effects of environmental heat on reproductive performance are greatest when cows are exposed to prolonged periods of extreme conditions within each 24 -h period. Thus, there is a need to assess the effects on reproductive performance of the total time cows are exposed to high environmental heat within each 24 -h period.

This study aimed 1) to identify those periods of exposure relative to service date in which the environmental heat load, assessed using the THI, was most closely associated with conception rates in lactating dairy cows, and 2) to assess whether the total time that cows are exposed to a high THI within each 24 -h period is more closely associated with conception rates than the maximum THI for each 24-h period.

\section{MATERIALS AND METHODS}

\section{Study Population}

This retrospective observational study used data from 26 year-round calving, predominantly HolsteinFriesian dairy herds from the Atherton Tableland, North Queensland. Associations between weather and conception rates were assessed using matings performed over a 21-mo period. All herds meeting the following criteria were selected: 1) the herd owner was a client of Tableland Veterinary Service; 2) the herd received monthly veterinary reproductive monitoring visits; 3) the herd was located within $30 \mathrm{~km}$ of the automated weather station used to collect weather data; 4) accurate cow records were maintained; and 5) bulls were not allowed to run continuously with the lactating herd.

\section{Service Selection}

All services, both AI and natural service, performed in lactating dairy cows in study herds from July 16, 2001 , to July 3 , 2003, inclusive, were used to explore the relationship between the monthly average of daily maximum THI and the conception rate for the month. For service-level statistical modeling, the date range for services was subsequently restricted to those performed from August 25, 2001, to April 30, 2003, inclusive. This ensured that weather data were available for each day from at least $40 \mathrm{~d}$ before to $64 \mathrm{~d}$ after each study service. Services in cows with no milk yield data for the study lactation, those of unknown age, or both were excluded from service-level statistical models. Before all analyses, services were excluded if 1 ) rectal examination results indicated that the service had occurred after the cow had conceived in that lactation; 2) the cow was culled $<46 \mathrm{~d}$ before the last monthly visit for the herd in the study period; 3 ) the service was $<46 \mathrm{~d}$ before the last monthly visit for the herd in the study period; or 4) the cow was not diagnosed as conceiving to service, but did not have either a negative pregnancy test from 35 to $200 \mathrm{~d}$ after service or a subsequent estrus within $200 \mathrm{~d}$ after the service.

\section{Definition of Conception}

Cows were artificially inseminated or naturally mated by "hand mating" according to the herd manager's usual practices. Where no subsequent estrus or service was recorded, cows were examined by manual rectal palpation, usually at the next monthly herd visit at least $35 \mathrm{~d}$ after service. In cows diagnosed as pregnant, the duration of pregnancy was estimated based on uterine horn diameter; sizes of amniotic vesicle, cotyledons, and fetus, and the presence of fremitus in uterine arteries, and the successful service was selected based on time since insemination. Of the services performed that were classified as successful, $89 \%(8,155 /$ 9,199 ) were diagnosed when palpated 35 to $70 \mathrm{~d}$ after service. Where a subsequent estrus or service was observed before the next herd visit, the cow was generally not examined at the next monthly herd visit. Services were classified as unsuccessful if the cow had a negative pregnancy diagnosis result when examined between 35 and $200 \mathrm{~d}$ after service or, in the absence of a negative pregnancy diagnosis result, if at least 1 subsequent estrus was recorded within $200 \mathrm{~d}$ after the service. Most unsuccessful services were followed by at least 1 estrus in the succeeding $200 \mathrm{~d}$. 


\section{Weather Data}

Ambient temperature (Temp), measured in degrees Celsius, and relative humidity $(\mathbf{R H})$, measured as a percentage, were obtained from records produced every 15 min by an automated weather recording station near Malanda (latitude $17^{\circ} 21^{\prime} \mathrm{S}$; longitude $145^{\circ} 36^{\prime} \mathrm{E}$ ), North Queensland, from July 16, 2001, to July 3, 2003, and average Temp and $\mathrm{RH}$ were calculated for each hour throughout the study period. These data were used to calculate the average dew-point temperature $\left({ }^{\circ} \mathrm{C}\right)$ for each hour using the following formula:

$$
\begin{gathered}
\text { dew-point temperature }=237.3 \\
\times \ln \left[\left(\frac{\mathrm{RH}}{100}\right) \times \text { exponential }\left(\frac{17.27 \times \mathrm{Temp}}{\mathrm{Temp}+237.3}\right)\right] / \\
\left\{17.27-\ln \left[\left(\frac{\mathrm{RH}}{100}\right) \times \text { exponential }\left(\frac{17.27 \times \mathrm{Temp}}{\mathrm{Temp}+237.3}\right)\right]\right\}
\end{gathered}
$$

\section{Measures of Environmental Heat Load}

Environmental heat load was described using the THI because thermoregulation in cows is affected by both Temp and RH (Armstrong, 1994) and heat load assessed using this index was previously associated with reduced milk yield in dairy cows in Australia (Mayer et al., 1999). The THI was calculated for each hour using the following formula:

$$
\mathrm{THI}=\text { temp }+0.36 \times \text { dew-point temperature }+41.2 .
$$

Two measures of heat load were defined for each 24$\mathrm{h}$ period. These were the maximum THI for the period (daily maximum THI) and the number of hours in the 24-h period when the THI was $>72$. This threshold was chosen based on the observed relationship between monthly average of the daily maximum THI and the crude conception rate for the month (Figure 1). Lower conception rates were observed in months when the average daily maximum THI was $>68$ to 70 , but the fitted line was approximately linear among months $>72$, so over this range, the fitted effect of each incremental THI unit was constant and additive. In previous Australian work, conception rates were lowest in seasons when the average THI was $>72$ to 74 (McGowan et al., 1996). For any single 24 -h period, the highest observed value for the daily maximum THI was 82 , and the greatest number of hours above the threshold THI of 72 was 18.

\section{Sources of Other Data}

Herd and cow identity numbers, calving dates, dates of birth, service dates, and type (AI or natural mating),

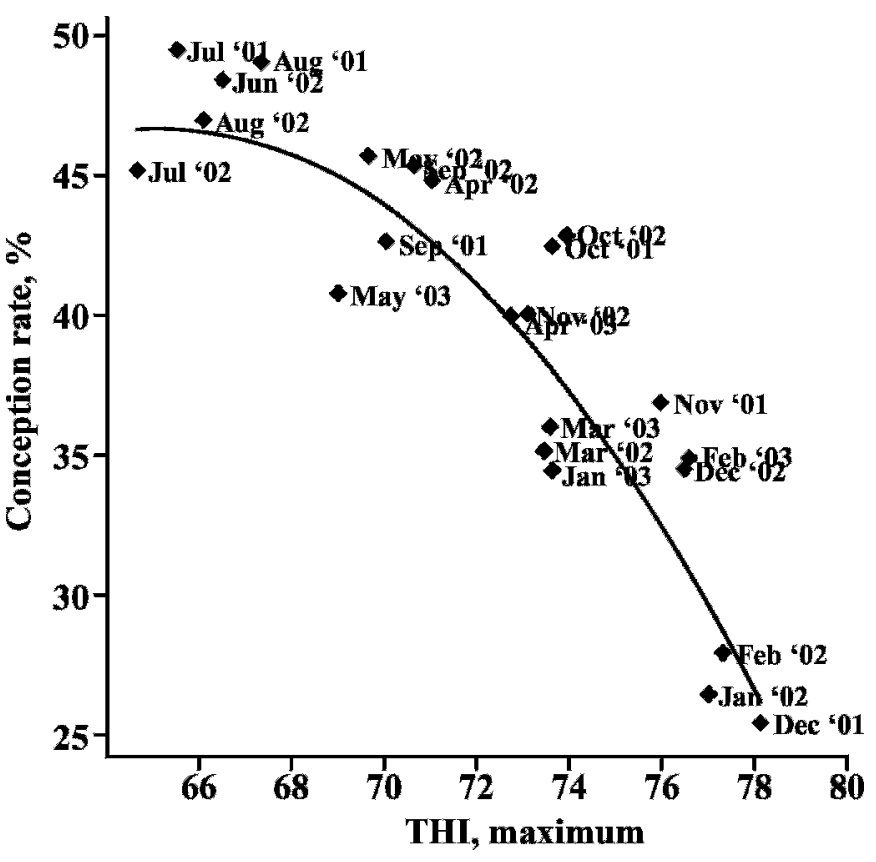

Figure 1. Association between monthly average of daily maximum temperature-humidity index (THI) and conception rate for services performed in lactating dairy cows during the month. Each point represents the conception rate (the proportion of services that resulted in pregnancy) for all services performed during the specified month. $R^{2}=0.821$.

dates, and results of reproductive examinations and culling and death data were obtained from computerized herd records managed using DairyWin (versions 32, then 2001; Massey University, Palmerston North, New Zealand).

\section{Preliminary Data Analyses}

The individual service was the unit of analysis. The outcome for each service was either conception or nonconception. Initial graphical and preliminary analyses were conducted using Genstat 8.2 (2005; Lawes Agricultural Trust, Rothamsted Experimental Station, UK). These included ordinary least squares regression in GLM using the normal distribution; generalized linear models using the binomial distribution and logit link (McCullagh and Nelder, 1989), and generalized linear mixed models incorporating a hierarchical error structure (Snijders and Bosker, 1999). These analyses identified a number of key features of this data set, including the following:

1. Heat load on days at least 1 mo before the day of service, and up to $2 \mathrm{wk}$ after the day of service were associated with the chance of conception.

2. Models using either measure of heat load (daily maximum THI and the number of hours in the day 
when the THI was above the threshold of 72) gave similar results.

3. For both measures of heat load, high autocorrelations existed between successive daily values, with correlation coefficients ( $r$ ) for a 1-d lag of 0.86 and 0.90 .

\section{Final Data Analyses}

Because of the degree of correlation between the heat load indices for various days, data were analyzed using ridge regression. This method is appropriate when exposure variables are highly correlated (Montgomery and Peck, 1982). Ridge regression adjusts the estimated coefficients toward their expectations had the exposure variables in fact been orthogonal; the method is closely related to Bayesian estimation. Because the outcome variable (conception) is binary in nature, ridge regression is only approximate because the method assumes a normal (rather than a binomial) distribution for the dependent variable. In addition, ridge regression uses only continuous variables and is a single-stratum regression model. Accordingly, variables identified in preliminary analyses as significantly associated with conception were coded using only the dominant binary contrast, and were fitted as fixed effects in the ridge regression models. These were cow age ( 2 to 4 yr vs. 5 yr and older), lactation number (first vs. subsequent), service number within lactation (1 to 3 vs. 4 or more), mating method (natural vs. AI), and overall adjusted conception rate for the herd, where herds were allocated to ranked groups according to their overall conception rates adjusted for all other terms in the preliminary generalized linear model: $\geq 52 \%(\mathrm{n}=4$ herds), 43 to $49 \%$ $(\mathrm{n}=4), 39$ to $41 \%(\mathrm{n}=6), 35$ to $38 \%(\mathrm{n}=6), 32$ to $33 \%$ $(\mathrm{n}=4)$, and $24 \%(\mathrm{n}=1)$. Calving to service interval was fitted as a linear term, with intervals longer than 200 $\mathrm{d}$ set to $200 \mathrm{~d}$ because previous work suggests that increases in conception rates with greater calving to service intervals do not occur when intervals are prolonged (J. Morton, unpublished data).

Separate ridge regressions were run for the 2 measures of heat load, namely, the daily maximum THI, and hours $>$ THI threshold of 72. For each, values for each day from $40 \mathrm{~d}$ before the day of service to $25 \mathrm{~d}$ after service were fitted along with the 10 variables for the other fixed effects: cow age, lactation number, service number within lactation, mating method, 5 dummy variables for overall adjusted conception rate category for the herds, and calving to service interval.

\section{RESULTS}

\section{Service Selected/Lost to Follow Up}

A total of 25,505 services (both AI and natural service) were performed in lactating dairy cows from July
16, 2001, to July 3, 2003. For service-level statistical modeling, the date range for services was subsequently restricted to those performed from August 25, 2001, to April 30, 2003, inclusive $(\mathrm{n}=21,900)$. Services were sequentially excluded if 1 ) rectal examination results indicated that the service had occurred after the cow had conceived in that lactation $(6.5 \%$ or $1,425 / 21,900)$; 2 ) the cow was culled $<46 \mathrm{~d}$ before the last monthly visit for the herd (1.8\% or 401/21,900); 3) the service was $<46 \mathrm{~d}$ before the last monthly visit for the herd $(0.3 \%$ or $74 / 21,900)$; or 4$)$ the cow was not diagnosed as conceiving to service, but did not have either a negative pregnancy test from 35 to $200 \mathrm{~d}$ after service or a subsequent estrus within $200 \mathrm{~d}$ after the service $(0.6 \%$ or $130 / 21,900)$. Services in cows with no milk yield data for the study lactation $(12.3 \%$ or $2,690 / 21,900)$ and of unknown age $(1.2 \%$ or $267 / 21,900)$ were also excluded, as were services on dates with incomplete weather data $(0.2 \%$ or $35 / 21,900)$, leaving 16,878 services $(77.1 \%$ or $16,878 / 21,900$ ) from 25 of the 26 study herds for analyses. Of the 16,878 services analyzed, 6,432 were successful, resulting in a conception rate of $38 \%$.

\section{Ordinary Least Squares Regression}

Figure 2 shows the fitted effects using the unadjusted ridge coefficients $(\mathrm{k}=0)$. These are not adjusted for autocorrelation in heat load between days and so are equivalent to ordinary least squares regression. These effect estimates are the estimated effects on conception rates given the maximum heat-load days (i.e., days with the highest observed maximum THI of 82 or 10 units above the threshold of 72 , and days with $18 \mathrm{~h}$ when the THI was $>72$, respectively, for the 2 measures of heat load) relative to days with zero heat load (i.e., a maximum THI of 72 or less and days with $0 \mathrm{~h}$ when the THI was $>72$, respectively). These estimates (Figure 2 ) were markedly confounded by heat load on other days because of the high degree of autocorrelation in heat load between days. The apparent "effect" of heat load fluctuated markedly on both sides of zero, with a notable degree of inconsistency in patterns for the 2 measures of heat load. Given 2 data sets each having 66 predictors, the 7 significant results $(6$ predicted declines and 1 predicted increase in conception rate) equal the random expectation $(P=0.05)$ of 7 . The only days when both THI measures were significant, and the days with the largest estimated declines in conception rate, were $d$ -16 and +19 , and these estimates appear unrealistically large relative to both Figure 1 and previous Australian work (McGowan et al., 1996).

\section{Ridge Regression Models}

In the principal component analyses that preceded the ridge regression analyses, for both the daily maxi- 


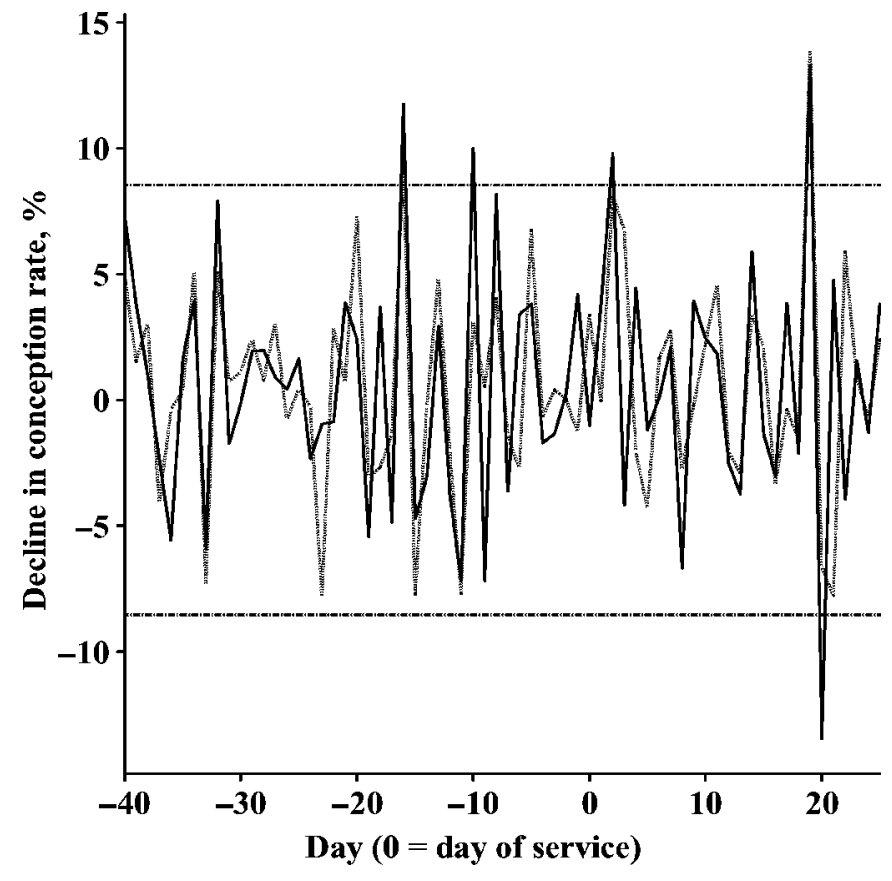

Figure 2. Fitted effects using ordinary least squares (i.e., not adjusted for autocorrelation in heat load between days) of 2 measures of heat load on conception rates in lactating dairy cows. The solid line is based on the daily maximum temperature-humidity index (THI); the dotted line is based on hours in the day when the THI was $>72$. Reported effects are for days with a maximum THI of 82 and days with $18 \mathrm{~h}$ when the THI was $>72$, respectively, for the 2 measures of heat load relative to days with zero heat load (maximum THI of $\leq 72$ and days with $0 \mathrm{~h}$ when the THI was $>72$, respectively). Fitted effects extending beyond the horizontal lines (-•-•) differ significantly $(P<0.05)$ from zero.

mum THI and hours $>72$, the first 10 (of 77) vectors accounted for more than $75 \%$ of the total variation, illustrating the high degree of correlation among exposure variables (i.e., between different days relative to service) and supporting the need for ridge regression.

When using ridge regression, there are a number of methods for choosing the adjustment $(\mathrm{k})$ coefficient. The high levels of correlation between exposure variables indicated that a high value of adjustment would be prudent. For our analyses, "optimal" values based on the index of stability of relative magnitudes and the numerical largeness of more significant regression coefficients (Vinod, 1976) were consistently in the high range (0.5 to 1.0). An alternative method (Montgomery and Peck, 1982) involves taking the value of $\mathrm{k}$ where the ridge traces stabilize (i.e., the value of $\mathrm{k}$ where, with further increases in $\mathrm{k}$, the THI coefficients do not change). This occurred only around the maximum adjustment $(\mathrm{k}=1.0)$. For both measures of heat load, the residual sums of squares for $\mathrm{k}$ of 1.0 were only $1.1 \%$ above the respective values when $\mathrm{k}$ was set at the midpoint of the optimal values based on the index of stabil-

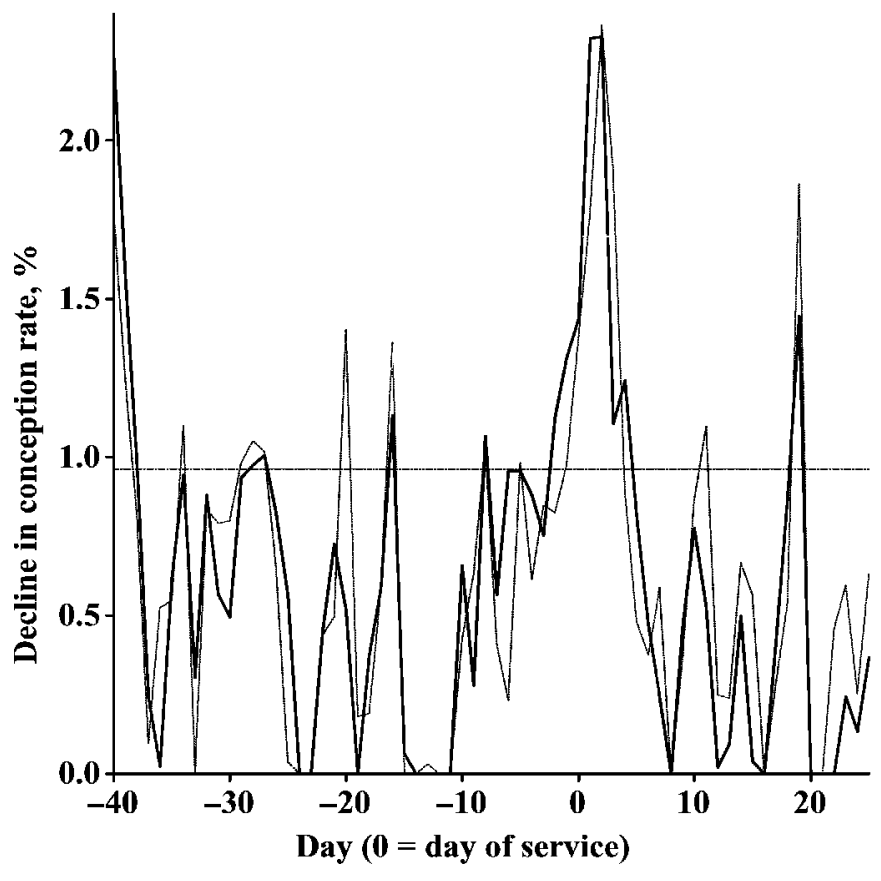

Figure 3. Fitted effects with adjustment for autocorrelation in heat load between days (using ridge regression) of 2 measures of heat load on conception rates in lactating dairy cows. The solid line is based on the daily maximum temperature-humidity index (THI); the dotted line is based on hours in the day when the THI was $>72$. Reported effects are for days with a maximum THI of 82 and days with $18 \mathrm{~h}$ when the THI was $>72$, respectively, for the 2 measures of heat load relative to days with zero heat load (maximum THI of $\leq 72$ and days with $0 \mathrm{~h}$ when the THI was $>72$, respectively). Fitted effects extending beyond the horizontal lines (-•-•) differ significantly $(P<0.05)$ from zero.

ity of relative magnitudes and the numerical largeness of more significant regression coefficients. This was within the 1 to $20 \%$ upper threshold recommended when using this alternative method (Montgomery and Peck, 1982). Hence, the most conservative adjustment $(\mathrm{k}=1.0)$ was adopted here.

Figure 3 shows these fitted effects, again for a maximum heat day. One-tailed tests were used because it was implausible that high environmental heat would increase conception rates. Twelve coefficients predicted increases in conception rates. These predicted increases were very small and not statistically significant $(P>$ 0.15 ), and were set back to zero in Figure 3. Models predicted similar results regardless of which measure of heat load was used. Day +2 stands out as having the single most extreme influence on the chance of conception. Rather than the exact location of each daily point, it is more appropriate to identify influential periods of consecutive days, represented as solid areas under the curves. In this regard, the first week (d 0 to $6 \mathrm{~d}$ after) had a major influence, but subsequent periods appeared relatively unimportant because predicted increases on 
most days after d 6 were small. Similarly, wk -1 was influential, but not so for wk -2 because predicted increases on $\mathrm{d} 8$ to 14 before the service were small. The higher peaks and solid areas under the curves in wk $-3,-4$, and -5 ( $\mathrm{d} 15$ to 35 before the service) indicated that there were longer term preceding effects.

\section{DISCUSSION}

These results demonstrate the importance of accounting for autocorrelation in heat load between days when assessing the effects of heat load on conception rates. Failure to account for this correlation resulted in substantial overestimation of the effect of heat load on particular days relative to the service day. Such overestimation is likely to occur in any data set in which a high degree of autocorrelation in exposure variables is present.

Because autocorrelation in heat load between days was accounted for in these analyses, the estimated effects for any particular day relative to the service day can be viewed as independent of effects on other days. For example, we estimated that conception rates would be reduced by about $2.5 \%$ if the day of service was a maximum heat-load day rather than a zero heat load day. Additional reductions in conception rates would occur if heat loads on preceding or succeeding days, or both, were also above zero. For example, if the maximum heat load occurred every day from $35 \mathrm{~d}$ before service to $6 \mathrm{~d}$ after service, we estimated that conception rates for these services would be reduced by around 30 percentage points relative to services in which there was no heat load from $35 \mathrm{~d}$ before service to $6 \mathrm{~d}$ after service. This total reduction was estimated as the sum of the reductions on each day in that period and assumed no interactions between days. Because heat load is highly autocorrelated between successive days, the observed reductions in conception rates in hot months, such as those demonstrated in Figure 1, reflect the cumulative effects of high heat load on the day of service combined with effects of heat load on the preceding and succeeding days, particularly from $35 \mathrm{~d}$ before service to $6 \mathrm{~d}$ after service.

These results indicate that weekly averages or totals summarizing daily heat load measures are adequate for describing heat load when assessing effects on conception rates in lactating dairy cows. The use of weekly averages or totals has advantages for statistical modeling because weekly variables will exhibit less autocorrelation than measures of daily heat load and so are more appropriate for use with statistical models that do not adjust for autocorrelation among exposure variables.

Daily maximum THI and hours above the THI threshold of 72 were highly correlated $(r=0.92)$, and results were similar for both heat load indices. To identify which of these indices are most closely associated with conception rates, further work is required in other regions where they are not so closely correlated. In the interim, it can be postulated that effects of THI on conception rates are more likely to be mediated through prolonged periods of time above the THI threshold of 72 than by a high daily maximum THI. Thus, where the 2 measures are not highly correlated, we suggest weekly total hours when the THI is $>72$ as the most useful index of heat load when assessing effects on conception rates in lactating dairy cows. In our study period, these weekly accumulations ranged between 0 and $97 \mathrm{~h}$, with an average of $31 \mathrm{~h}$.

These study findings suggest that conception rates are reduced when cows are exposed to a high THI either before or after service. Week 1 appears particularly important, but subsequent periods appear relatively unimportant. Week -1 is highly influential, and high heat loads in wk -3 to -5 also appear important. These findings are consistent with evidence from intervention studies showing that reductions in conception rates in hot periods are due to the combined effects of environmental heat over prolonged time periods rather than on single days around the day of service. Whereas cows exposed to environments with a range of cooling systems for prolonged periods have higher conception rates than uncooled cows (Thompson et al., 1996), cooling for 7 - to 16 -d periods commencing 1 to $3 \mathrm{~d}$ before service has not resulted in large increases in conception rates (Ealy et al., 1994). The effects of heat loads in these weeks appear cumulative, with observed reductions in conception rates in hot weather reflecting the additive effects of heat load from wk -5 to wk 1 .

High ambient temperatures have a number of detrimental effects on physiological processes that are important for the establishment and maintenance of pregnancy after fertilization. These effects have been reviewed (Wolfenson et al., 2000; De Rensis and Scaramuzzi, 2003) and include impaired oocyte quality and embryo development, increased embryonic mortality, endometrial dysfunction, impaired steroidogenesis in ovarian follicles and corpora lutea, loss of normal follicular dominance patterns, and reduced uterine blood flow. These effects can occur concurrently with other effects of heat load such as reduced DMI and increased negative energy balance, factors that may affect reproductive performance.

Our observations suggest that the effects of high heat load are greatest in the week leading up to service and in the week after service. Mechanisms for the effects of exposure prior to service are unclear, but may be due to suppression of inhibin production by the dominant follicle, leading to earlier emergence of a preovulatory 
follicle, with consequent lower fertility (Wolfenson et al., 1995). This effect would be expected to be effective 7 to $10 \mathrm{~d}$ prior to the service date. Heat load during the maturation of oocytes induces apoptotic changes (Roth and Hansen, 2004) and disrupts nuclear maturation (Roth and Hansen, 2005). The effects of exposure on the day of service may be due, in part, to a reduced chance of fertilization if sperm transport to the oviduct is impaired by heat load on the day of service.

Acute exposure to heat load may also affect survival of the conceptus but results of this study and previous work suggest that these effects are most important following exposure soon after conception. Ju et al. (1999) showed that 4-d-old embryos were more resistant to heat load than 3-d-old embryos, and Ealy et al. (1995) showed that morulae at $d 5$ were more resistant than 2-cell embryos. However, although older embryos appear to be more tolerant to heat load, there is some evidence that heat load in early gestation increases the risk of fetal loss; exposure of cows to high THI in d 21 to 30 of gestation has recently been associated with increased fetal losses between d 34-45 and d 90 (GarcíaIspierto et al., 2006). In the current study, most successful services were diagnosed as such between 35 and 70 $\mathrm{d}$ after service. Thus, any effects of heat load on fetal loss after this time were not studied.

The observed effects in wk $-3,-4$, and -5 are consistent with previous work in which $5 \mathrm{~d}$ of heat exposure affected steroid production and the characteristics of follicles collected 20 to 26 d later (Roth et al., 2001). In other work, oocyte development was reduced following collection in summer months, and short-term exposure of oocytes to the THI had additional detrimental effects (Al-Katanani et al., 2002). Seasonal variations in follicular steroid hormone concentrations have been reported, and these may have detrimental effects on conception and the maintenance of pregnancy (Wolfenson et al., 1997). Accumulated effects of exposure to a high THI before $\mathrm{d}-40$ are captured in the estimated conception rate declines of 2.2 and $1.7 \%$ for the maximum daily THI and hours above the THI threshold of 72 , respectively, on $d-40$. These estimates indicate that exposure to a high THI more than $40 \mathrm{~d}$ before service has adverse effects on conception rates, but that accumulated exposure $>40 \mathrm{~d}$ before service is less important than accumulated exposure closer to and soon after the service date.

These findings have important implications for the management of lactating dairy cows in hot, humid climates. For the maximum effect, management interventions to ameliorate the effects of heat load on conception rates should be implemented at least $5 \mathrm{wk}$ before anticipated service and should continue until at least $1 \mathrm{wk}$ after service. Thus, where hot, humid weather persists for weeks or months and mating periods are prolonged, such interventions must continue for long periods.

In herds with mating periods in hot, humid weather, managers must assess whether to inseminate cows diagnosed in estrus. These study findings indicate that such decisions should be based not only on weather on the day of estrus diagnosis, but also on weather for the preceding $5 \mathrm{wk}$ as well as forecast weather for the ensuing week. The associations with weather in wk -1 to -5 raise the possibility that models based on weather up to the day of estrus may have sufficient predictive ability to assist managers in assessing the economic consequences of withholding service in hot weather. Withholding service requires careful consideration because conception can be delayed substantially, putting cows at risk for premature culling (Rajala Schultz and Grohn, 1999). Thus, careful economic appraisal is warranted, and such a model may be an important aid for this purpose.

\section{CONCLUSIONS}

When assessing the effects of heat load on conception rates, autocorrelation in heat load between days should be accounted for in analyses. Weekly averages or totals summarizing the daily heat load are adequate to describe heat load when assessing the effects on conception rates in lactating dairy cows and will exhibit less autocorrelation than daily heat load measures. Where daily maximum THI and hours when THI is $>72$ are highly correlated, as in the current study period, associations with the probability of conception are similar.

Conception rates are reduced when cows are exposed to a high heat load either before or after service. The week from day of service to $6 \mathrm{~d}$ after service appears particularly important, as does wk -1 . Heat loads in wk -3 to -5 are also associated with reduced conception rates. Thus, management interventions to ameliorate the effects of heat load on conception rates should be implemented at least $5 \mathrm{wk}$ before anticipated service and should continue until at least 1 wk after service. The associations with weather in wk -1 to -5 raise the possibility that models based on weather up to the day of estrus may have sufficient predictive ability to help managers assess the economic consequences of withholding service in hot weather.

\section{ACKNOWLEDGMENTS}

We greatly appreciate the efforts of the farmers who managed the study herds; the veterinarians who completed the monthly farm visits: Ian Bradshaw, Erica Ayres, Alison Gunn, and Ian Hosie; Kay Dodds for data 
entry; and Tom De Ridder for data preparation. The study was partly funded by Dairy Australia.

\section{REFERENCES}

Al-Katanani, Y. M., F. F. Paula-Lopes, and P. J. Hansen. 2002. Effect of season and exposure to heat stress on oocyte competence in Holstein cows. J. Dairy Sci. 85:390-396.

Al-Katanani, Y. M., D. W. Webb, and P. J. Hansen. 1999. Factors affecting seasonal variation in 90-day nonreturn rate to first service in lactating Holstein cows in a hot climate. J. Dairy Sci. 82:2611-2616.

Armstrong, D. V. 1994. Heat stress interaction with shade and cooling. J. Dairy Sci. 77:2044-2050.

Cavestany, D., A. B. El Wishy, and R. H. Foote. 1985. Effect of season and high environmental temperature on fertility of Holstein cattle. J. Dairy Sci. 68:1471-1478.

De Rensis, F., P. Marconi, T. Capelli, F. Gatti, F. Facciolongo, S. Franzini, and R. J. Scaramuzzi. 2002. Fertility in postpartum dairy cows in winter or summer following estrus synchronization and fixed time AI after the induction of an LH surge with GnRH or hCG. Theriogenology 58:1675-1687.

De Rensis, F., and R. J. Scaramuzzi. 2003. Heat stress and seasonal effects on reproduction in the dairy cow-A review. Theriogenology 60:1139-1151.

Ealy, A. D., C. F. Arechiga, D. R. Bray, C. A. Risco, and P. J. Hansen. 1994. Effectiveness of short-term cooling and vitamin $\mathrm{E}$ for alleviation of infertility induced by heat stress in dairy cows. J. Dairy Sci. 77:3601-3607.

Ealy, A. D., J. L. Howell, V. H. Monterroso, C. F. Arechiga, and P. J. Hansen. 1995. Developmental changes in sensitivity of bovine embryos to heat shock and use of antioxidants as thermoprotectants. J. Anim. Sci. 73:1401-1407.

García-Ispierto, I., F. López-Gatius, P. Santolaria, J. L. Yániz, C. Nogareda, M. López-Béjar, and F. De Rensis. 2006. Relationship between heat stress during the peri-implantation period and early fetal loss in dairy cattle. Theriogenology 65:799-807.

Ingraham, R. H. 1973. Estimation of conception rate depression of Holstein cows due to adverse temperature and humidity in tropical and subtropical climates. Int. J. Biometeorol. 17:131-134.

Ingraham, R. H., R. W. Stanley, and W. C. Wagner. 1976. Relationship of temperature and humidity to conception rate of Holstein cows in Hawaii. J. Dairy Sci. 59:2086-2090.

Jonsson, N. N., W. J. Fulkerson, P. M. Pepper, and M. R. McGowan. 1999. Effect of genetic merit and concentrate feeding on reproduction of grazing dairy cows in a subtropical environment. J. Dairy Sci. 82:2756-2765.

Jonsson, N. N., M. R. McGowan, K. McGuigan, T. M. Davison, A. M. Hussain, M. Kafi, and A. Matschoss. 1997. Relationships among calving season, heat load, energy balance and postpartum ovula- tion of dairy cows in a subtropical environment. Anim. Reprod. Sci. 47:315-326.

Ju, J. C., J. E. Parks, and X. Yang. 1999. Thermotolerance of IVMderived bovine oocytes and embryos after short-term heat shock. Mol. Reprod. Dev. 53:336-340.

Lopez-Gatius, F. 2003. Is fertility declining in dairy cattle? A retrospective study in northeastern Spain. Theriogenology 60:89-99.

Mayer, D. G., T. M. Davison, M. R. McGowan, B. A. Young, A. L. Matschoss, A. B. Hall, P. J. Goodwin, N. N. Jonsson, and J. B. Gaughan. 1999. Extent and economic effect of heat loads on dairy cattle production in Australia. Aust. Vet. J. 77:804-808.

McCullagh, P., and J. A. Nelder. 1989. Generalized Linear Models. 2nd ed. Chapman and Hall, London, UK.

McGowan, M. R., D. G. Mayer, W. Tranter, M. Shaw, C. Smith, and T. M. Davison. 1996. Relationship between temperature humidity index and conception efficiency of dairy cattle in Queensland. Proc. Aust. Soc. Anim. Prod. 21:454.

Montgomery, D. C., and E. A. Peck. 1982. Introduction to Linear Regression Analysis. John Wiley and Sons, New York, NY.

Rajala Schultz, P. J., and Y. T. Grohn. 1999. Culling of dairy cows. Part III. Effects of diseases, pregnancy status and milk yield on culling in Finnish Ayrshire cows. Prev. Vet. Med. 41:295-309.

Roth, Z., A. Arav, A. Bor, Y. Zeron, R. Braw-Tal, and D. Wolfenson. 2001. Improvement of quality of oocytes collected in the autumn by enhanced removal of impaired follicles from previously heatstressed cows. Reproduction (Cambr.) 122:737-744.

Roth, Z., and P. J. Hansen. 2005. Disruption of nuclear maturation and rearrangement of cytoskeletal elements in bovine oocytes exposed to heat shock during maturation. Reproduction (Cambr.) 129:235-244.

Roth, Z., and P. J. Hansen. 2004. Involvement of apoptosis in disruption of developmental competence of bovine oocytes by heat shock during maturation. Biol. Reprod. 71:1898-1906.

Snijders, T. A. B., and R. J. Bosker. 1999. Multilevel Analysis. An Introduction to Basic and Advanced Multilevel Modelling. Sage Publications, London, UK.

Thompson, J. A., D. D. Magee, M. A. Tomaszewski, D. L. Wilks, and R. H. Fourdraine. 1996. Management of summer infertility in Texas Holstein dairy cattle. Theriogenology 46:547-558.

Vinod, H. D. 1976. Application of new ridge regression methods to a study of Bell system scale economies. J. Am. Stat. Assoc. 71:835-841.

Wolfenson, D., B. J. Lew, W. W. Thatcher, Y. Graber, and R. Meidan. 1997. Seasonal and acute heat stress effects on steroid production by dominant follicles in cows. Anim. Reprod. Sci. 47:9-19.

Wolfenson, D., Z. Roth, and R. Meidan. 2000. Impaired reproduction in heat-stressed cattle: Basic and applied aspects. Anim. Reprod. Sci. 60-61:535-547.

Wolfenson, D., W. W. Thatcher, L. Badinga, J. D. Savio, R. Meidan, B. J. Lew, R. Braw-Tal, and A. Berman. 1995. Effect of heat stress on follicular development during the estrous cycle in lactating dairy cattle. Biol. Reprod. 52:1106-1113. 